\title{
Concept for Optimization and Simulation of renewable energy parks with desalination
}

\author{
*D. Buschert \\ B. Bitzer \\ South Westphalia University of Applied Sciences, Campus Soest, \\ Lübecker Ring 2, 59494 Soest, Germany \\ Buschert@fh-swf.de \\ Bitzer@fat-soest.de
}

\begin{abstract}
This paper is about the concept of the combination of renewable energy parks and water desalination. During the energy production a lot of waste heat is produced which is in the majority of cases unused. The needed (waste) heat for the water desalination unit can be generated with biomass power plants, geo thermal or solar power. So the idea is to use this unused energy to convert saltwater into freshwater. This water can be used to irrigate fields or to produce common products. The advantage is that the produced water and energy can be used independent from each other.

The current project is about the optimization between the water desalination unit from the company Terrawater [5] and the produced waste heat from a renewable energy source. At first there will be coded a simulation programme for a physical mathematical model. Furthermore a control programme will be written which works together with the simulation programme to control the heat flow volume from the power plant or heat generator to the desalination unit to get the best performance and a best amount of freshwater. During the simulation process a lot of different aspects have to be regarded and they have to be included in the control programme.
\end{abstract}

\section{Keywords}

renewable energy, water desalination, combination, optimization and simulation programme

\section{Introduction}

In the next years the needed energy and freshwater will rise worldwide [1]. So there has to be found alternatives to the existing centralized power plants and the freshwater supply. Transportation of energy and water along far distances causes investments and losses and this is not needed for decentralized energy parks Also the leakages in the water pipes are similar for loss of water, because of bad maintenance due to high costs of the maintenance. One problem in developing countries is that a lot of freshwater is contaminated with dangerous ingredients like oil or excrements and other wastes, so this water cannot be used for drinking, washing and daily usages. At the moment there are already problems with

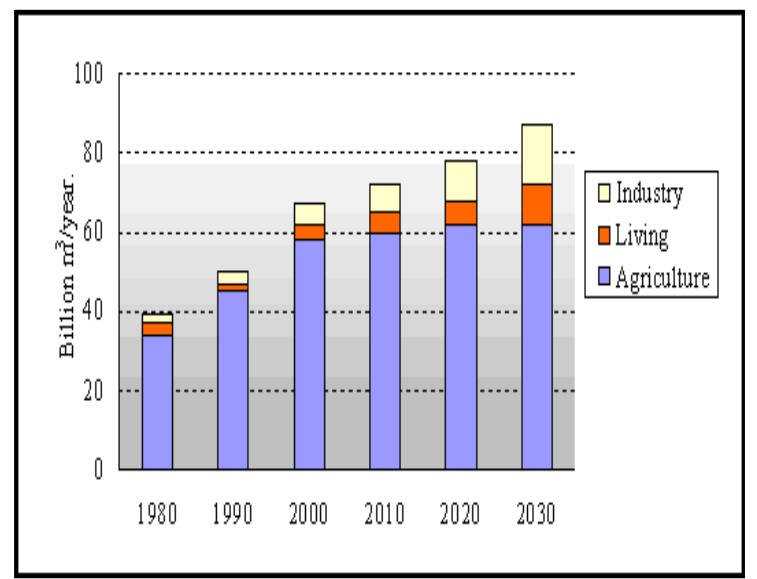

Fig. 1: Worldwide consumption of water; Agriculture, Industry and Household

the supply of freshwater and energy, not only in the $3^{\text {rd }}$ world as in India or Africa but also in some parts of Europe. For example in the last years in South Europe there have been droughts, so there were problems to irrigate the fields to produce crop plants. A lot of plants are dried up, resulting in high financial penalties. Additional a lot of people around the world do not have enough water or energy for everyday requirements. Because of the water shortage in many regions a lot of people die of thirst. In some territories, for example in India, they do not have a basic supply of energy, because there are no power plants or grids. Without electrical energy it is very difficult to get water without transporting it with trucks or alternatively to go to a standpost. The next problem arises, if it is a deep well. So it is very difficult to scoop water. As can be seen in figure 1, the worldwide consumption of water will rise in the next years. In the year 2000 the required demand of freshwater was round about 6500 billion $\mathrm{m}^{3}$. In 2025 the estimated amount of needed freshwater will be more than 8500 billion $\mathrm{m}^{3}$, it is an increase by $30 \%$ from the year 2000. In the remote future it is much, much more. The agriculture uses the most of the estimated freshwater. 


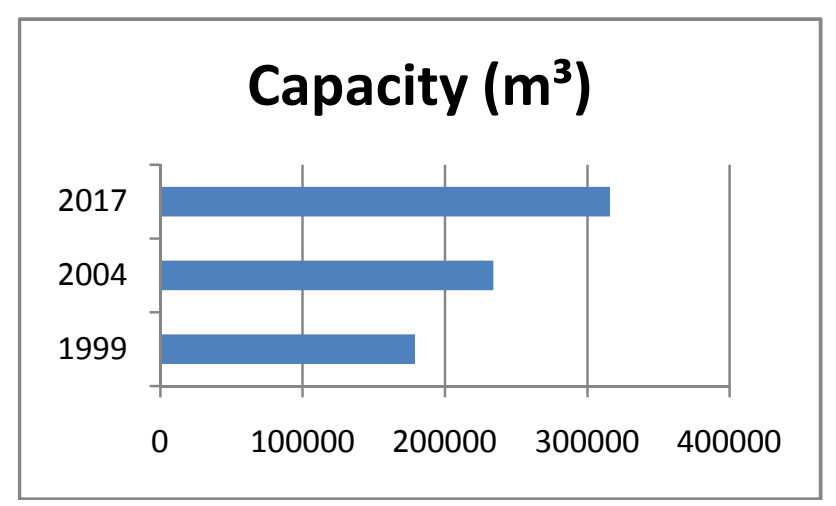

Fig. 2: Plan of water desalination in Egypt

Then follows the industry and on the last place are the households. This are enough arguments to produce freshwater with a high quality and to deliver it to those people who have an undersupply of water. The production of freshwater should be cheap, secure and the desalination apparatus (and the needed power plan) should work for a long time without a lot of maintenance operations. Another example for the importance of the water desalination is shown in the figure 2 . In the year 1999 more than $178.917 \mathrm{~m}^{3}$ freshwater was produced in Egypt with water desalination units. Five years later more than $233.963 \mathrm{~m}^{3}$ water was converted in that way. In the year 2017 the estimated water desalination rate could be $315.850 \mathrm{~m}^{3}$. So there is a high annual rate of growth and a high financial potential for the future.

On the other hand, a lot of people do not have a supply of energy. They live in isolated areas without a power supply. The next power station is far away and so it is uninteresting for the power plant operators to build power supply lines, because of the high financial costs for the installations. So those people do not have a chance to get electricity and they go without it. One option is to build decentralized and small power stations to sustain those people who are close to this station. So they can be supplied with energy and live a relative comfortable life. For saving the environment it is a good idea to use renewable energy plants for example biomass power plants, wind generators or photovoltaic. Biomass power plants only produce carbon - dioxide as much as the raw materials had absorbed during the growth. So this energy production is environmentally neutral and it is not conductive to the global warming.

One idea is to build biomass power plants in isolated areas, because the needed fuel is very easy to get and the route of transport is relative short. It is dispersed all over the world and so it is very cheap and fast to get. Because of the local availability the transport costs are also very low and this causes low priced energy [4]. On the other side you are independent on the OPEC and other gas or oil exporting countries, like Russia. This is a security of supply for a relative long period of time, because no governments can stop the delivering of needed fossils or can put the screw on the supplied states to force the government officials to do something, as could be seen in the Ukraine in the last weeks.
There a two different situation, if you want to build a complex of buildings to supply those people with water and energy who life in the neighbourhood. The first one is a green field installation. There are no existing grids or utility services which have the advantages that you can start from scratch and realize one's own ideas, like in isolated areas. On the other hand there are existing infrastructures, but they cannot produce enough water and energy to supply all people or the existing energy and water production is environmental unfriendly and obsolete. If there are infrastructures it is recommendable to build on it because this can be more profitable, but you have to use existent infrastructures and so you cannot realize all your own ideas. If you will realize your one's own ideas anyway, then it could be much more expensive.

With biomass power plants and solar power the energy production is $\mathrm{CO}_{2}$ neutral and this is very important at present time, because of the possibility of global warming. With biomass power plants it is also very easy to vary the energy output [4]. During this energy generation a lot of waste heat is produced, which can be used for other applications. At this moment this waste heat is released to the environment or seas and rivers and so this precious energy is lost. There are few aspects or ideas to raise the degree of efficiency and so you can earn much more money.

\section{Our project idea}

So the new aspect and the particular in our project is that this waste heat is used to clean or desalinate water. In countries with a high sun radiation it could also be possible to use solar thermal to produce the needed heat for the desalination. The later realization in an hotel project could be a combination of a biomass power plant for the base load and solar thermal for the peak loads during the noonday and the afternoon. With this combination of renewable energy source and water desalination it is possible to produce energy and water in an environmental neutral way and to enhance the energy yield. In this way less energy is dissipated and so the environment will be protected. Another advantage and the particular in this project regarding to other projects is that the produced water and energy can be used independent from each other unlike other water desalination methods. This combined apparatus can be built in isolated areas and sustain those people who needed water and energy. Thus the basic supply can be guaranteed.

One other idea is to build a self - sustaining hotel which can be advertised as a green or eco hotel. For the implementation in our future projects the load profiles for different applications have to be analysed. The required data are the daily, monthly and yearly characteristically demand of freshwater and energy in the tourism sector for example in Egypt. The data obtained have to be statistically evaluated to find a possible and cheap realization. Our considered decision is to use the water desalination unit from the German Firm Terrawater 
which uses evaporation to desalinate saltwater or brackish water. The advantage of this desalination unit is that it do not need a lot of electrical energy to convert saltwater into freshwater like the reverse - osmosis systems or the membrane - distillation. Another benefit is that no chemicals or expensive membranes are used and furthermore the maintenance is very long. It can be several months. The needed heat or energy for the desalination can be a waste product from the industry or from power plants. This offers a good combination of waste heat producing power plants and the water desalination. On the one hand people can get power for their daily use and on the other hand they can get freshwater unlike with the other possibilities. With this combination a few of the 80 million Indian people without a power supply can be supplied with electricity and freshwater. The needed construction can be build in isolated territories and may be constructed as a green field installation or can use existing infrastructures.

The influencing variables in our project are the raw water temperatures, the pressure inside of the water desalination unit, the (waste) heat temperature and the water consumption. Additionally there are further variables which are not listed before. Precondition for the worldwide achievement of this project is that the produced water can be sold beneficial and the costs for the energy generation keep up with the local power producers.

Another challenge of this project is to simulate and optimize the amount of (waste) heat which comes from a renewable energy source which is used to desalinate saltwater or to clean wasted water in the desalination unit. For the best performance of the desalination unit the temperature and the flow of the (waste) heat have to be coordinated. For this reason a simulation programme has to be written to find the optimum for different raw water temperatures, (waste) heat temperatures, the pressure inside of the desalination unit and the amount of the (waste) heat flow. Figure 3 shows the different components which are necessary to control and to operate this combination of water desalination unit and power plant. Under the term "Hardware" the water desalination unit and the power plant is consolidated. From this several real time data are measured and they will be evaluated in the "Monitoring, Controlling" component. With the "Simulation" module the "Monitoring, Controlling" component will adjust the water desalination and the power plant to the optimum. If an error occurs, this should be seen on the measured data or otherwise an error message is sent from the Hardware to the "Monitoring, Controlling" module, this module will send this information to the module for the "Error Handling". This module starts to find a solution and / or will switch the Hardware via the "Monitoring, Controlling" module into a save mode. The chosen solution depends on the occurred problem(s). Furthermore the "Error Handling" module will send the error massage and the temporary solution via the internet to the maintenance service and / or it will send a message to the mobile phone of the operator of this station. So a remote maintenance can be established or the damaged

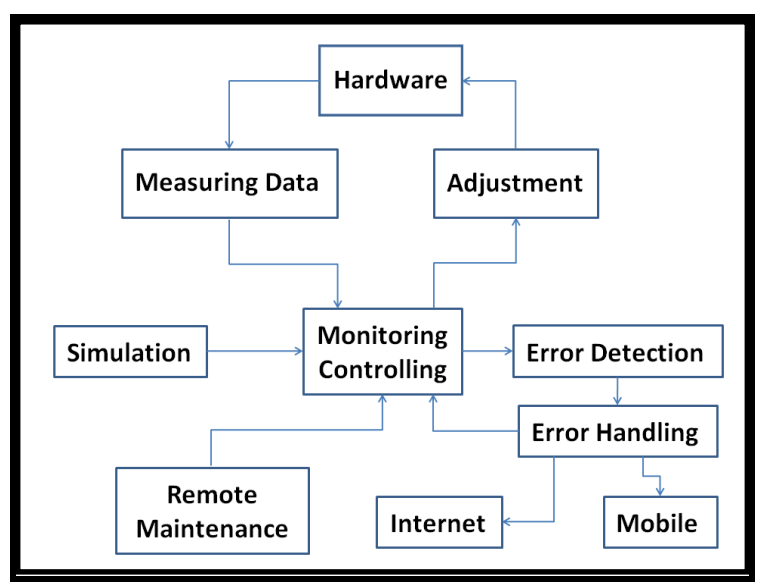

Fig. 3: Software and Hardware modules for this project

parts can be replaced shortly by the attendance team. Furthermore programme updates can be done via the "Remote Maintenance" module to improve the effectiveness.

Figure 4 shows the three - phase diagram of water in the range in which the water desalination unit works. The working temperature of the desalination unit is up to $95{ }^{\circ} \mathrm{C}$. The phase diagram is a technical aid in physics which shows different conditions and the associate phases. The three phases are defined as solid, liquid and gas. On the boundary lines two phases are existent (solid and gas, solid and liquid or liquid and gas). At the triple point all three phases solid, liquid and gas are present. For different pressures and temperatures the phase of water can be found in the diagram. For example for $20{ }^{\circ} \mathrm{C}$ and 1 atmosphere the phase of water is liquid, but for $20^{\circ} \mathrm{C}$ and 0.006 atmospheres the phase of water is gas. The critical point is defined as the pressure and the temperature, where the density becomes equal. The difference between both states of aggregation, liquid and gas, are undistinguishable, but this area is uninteresting for this project, because the water desalination unit do not work in this area.

The estimated energy demand for the water desalination unit is for $1 \mathrm{~m}^{3}$ water from $2.5 \mathrm{~kW}_{\mathrm{el}}$ till $3.5 \mathrm{~kW}_{\mathrm{el}}$. Additional the heat capacity to be made available for $1 \mathrm{~m}^{3}$ is between $180 \mathrm{~kW}_{\text {th }}$ and $360 \mathrm{~kW}_{\text {th }}$. The operation power for one hour is between $10 \mathrm{~kW}_{\text {th }}$ and $90 \mathrm{~kW}_{\text {th }}$, it depends on the given preconditions of the raw water. One desalination unit can produce in the range from 60 to 2501 freshwater per hour [5].

Water has one of the highest effective heat capacities. It is higher than for most of all other known materials. The effective heat capacity of water is $\mathrm{c}=4185 \mathrm{~J} \mathrm{~kg}^{-1} \mathrm{~K}^{-1}$. The effective heat capacity is a measure to heat a material from temperature $T_{1}$ to another temperature $T_{2}$. If you want to raise the temperature of 1 litre water for example from $20^{\circ} \mathrm{C}$ to $21^{\circ} \mathrm{C}$ you need the energy $\mathrm{E}=4185 \mathrm{~J}$. If you want to raise the temperature again from $21{ }^{\circ} \mathrm{C}$ to $22{ }^{\circ} \mathrm{C}$ you need again $4185 \mathrm{~J}$ and all the rest of it. For this heating you have to supply it with power. This can be electrical energy transformed into thermal energy or direct thermal energy from energy generators, like power 
plants or from the industry. Another possibility is to use solar power or geo thermal. This energy demand is also known as calorie. So a lot of energy is needed to desalinate water. The higher the temperature of the water, the better is the water desalination. In combination with a lower pressure, it could be a very interesting aspect.

This water desalination units uses evaporation to convert saltwater or brackish water into freshwater. The following formula describes the evaporation of water on open expanse of water or good provided areas with water. A lot of different applications use this equation to estimate the potential evapotranspiration from water and land. Its widely regarded as one of the most accurate models. The needed energy in this formula can be provided by waste heat or thermal heat.

The formula for the evaporation is the following and it is known as Penman - Equation:

$$
E=\frac{\Delta\left(R_{n}-G\right)+\rho_{L} c_{p} C_{a t} \delta_{e}}{\lambda_{W}(\Delta+\gamma)}
$$

where:

$$
\begin{aligned}
& E=\text { Rate of evaporation }\left(\mathrm{kg} \mathrm{m}^{-2} \mathrm{~s}^{-1}\right) \\
& \Delta=\text { Slope of the saturation vapour pressure } \\
& \quad \text { curve }\left(\mathrm{Pa} \mathrm{K} \mathrm{K}^{-1}\right) \\
& R_{n}=\text { Net irradiance }\left(\mathrm{W} \mathrm{m}^{-2}\right) \\
& G=\text { Soil heat flux }\left(\mathrm{W} \mathrm{m}^{-2}\right) \\
& \rho_{L}=\text { Density of air }\left(\mathrm{kg} \mathrm{m}^{-3}\right) \\
& c_{p}=\text { Heat capacity of air }\left(1004 \mathrm{~J} \mathrm{~kg}^{-1} \mathrm{~K}^{-1}\right) \\
& C_{a t}=\text { Atmosspheric conductance }\left(\mathrm{m} \mathrm{s}^{-1}\right) \\
& \delta_{e}=\text { Vapour pressure deficit }(\mathrm{Pa}) \\
& \gamma=\text { Psychometric constant }\left(\mathrm{ca} .0 .6 \mathrm{hPa} \mathrm{K}^{-1}\right) \\
& \lambda_{W}=\text { Latent heat of vaporization }(2.5 \mathrm{MJ} \mathrm{kg})
\end{aligned}
$$

The standard raw water temperature from seas and brackish water is between $0{ }^{\circ} \mathrm{C}$ and $30^{\circ} \mathrm{C}$ and the pressure at sea level is between 900 mbar and 1100 mbar, it depends on the atmospheric conditions, if there is a high - pressure or a low - pressure area. So there are different possibilities to improve the water desalination, which can be derived from the figure 4. One Option is to raise the temperature of the salt or raw water, so that freshwater can be produced with evaporation. One other idea is to lower the pressure over the saltwater to force a phase jump from liquid to gas. Afterwards this gas can be liquefied and you get freshwater. The third option is a combination of these two aspects. It could be possible to raise the temperature of the saltwater or the raw water and lower the pressure over the liquid. This could be more effective than the two single possibilities.

The water desalination unit only needs temperatures lower than $95^{\circ} \mathrm{C}$. The needed energy for the desalination depends on the raw water temperature. Warmer water needs less energy than colder water. If the temperature of the (waste) heat is to high it can be cooled with surrounding air or if the flow is to low it has to be compressed to the needed density. On the other side it

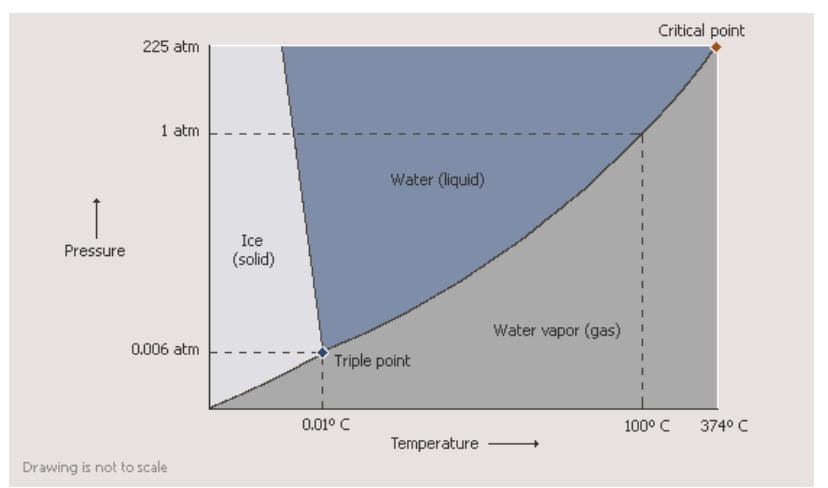

Fig. 4: three - phase diagram of water [9]

has to be expanded, if the density is too high. In this vein the efficiency of the apparatus can be raised. Maybe it can be possible to store the produced (waste) heat to run the desalination unit $24 \mathrm{~h}$ per day. During the night less energy is needed and so less waste heat is produced which can be used for desalination.

The simulation and the mentioned optimization can be done with the software ASPEN [7], Maple [8] and / or particle swarm optimization. If solar power is used for producing waste heat or energy a few calculations can be done with the programme TRANSYS [2], [3]. With this modular build-on and dynamical building and construction simulation programme it is possible to coordinate the components like the pumps and solar collectors in the solar power circuit. Newer projects use TRANSYS to simulate water desalination units, too. For this, different existing modules have to be arranged in an unusual manner and they have to be related to each other. These gathered data have to be converted to use for the simulation programme which was mentioned before. With this data an upscaling for larger projects all over the world and for a lot of preconditions is possible. The produced energy and freshwater can be sold to the consumer or can be used for other applications like irrigating field or for industry. And this is a way for the owner of the power station to enhance their profits. It can also be very interesting for companies with a high $\mathrm{CO}_{2}$ generation, because they can build such a kind of combination and so they can acquire $\mathrm{CO}_{2}$ certificates which are very important at the moment.

After the simulation process a control programme has to be coded which will control the flow of the (waste) heat to the water desalination unit and it will also control the flow of the saltwater in order that the generation of freshwater is near the optimum. A scheme of the control programme can be found in figure 3. The control programme can be written in the programme LabVIEW from National Instruments [6] and will use the results of the physical - mathematical simulation to adjust the installation. The produced data from different sensors will be collected, evaluated and so the programme can control the different pumps, different valves and all other possible settings. This programme can also be used to monitor the application. In the control programme there will also be an error detection included. It is also possible to do an attendance and fine adjustments via the internet 
from all over the world to get a higher efficiency, switch to another configuration, include newer research results or to solve smaller problems. Thus there are only a few dead times and less lose of gains. The feature to other projects is that the construction can work for a long time without a monitoring team, because the service interval is very long. It can be several months and much longer.

\section{Conclusion}

The idea to combine a water desalination with renewable energy sources could be very interesting. During the power generation a lot of waste heat is produced. Nowadays this energy is unused, but it can be used for a reasonable application. With this combination a lot of freshwater can be produced without using other resources. With this water a lot of people in dry countries can be helped to cover their basic needs of freshwater. Furthermore no carbon dioxide is produced and this saves the environment. Additional the use of renewable energy sources reduces the annual production of carbon dioxide, too.

This combination of renewable energy sources and the water desalination is a ideal combination. Water and energy can be used independent from each other and can supply people in isolated territories. This construction can be built as a Greenfield installation or can be combined with existing infrastructures. Additional it can be built in hotels or pensions and then they can be advertised as green or eco hotels.

For a good combination of the water desalination unit and the heat generator a physical - mathematical simulation must be done. Furthermore a controlling and monitoring programme have to be coded to control these combination to adjust it to the best performance. This adjustment works in combination with the mentioned simulation to find an optimum between the provided energy and the raw water.

The estimated costs for one litre fresh water can be a few cent. Due to a limitation of time and missing information no further information can be given at the moment but it will be caught up.

\section{Contact}

For further information do not hesitate to contact the authors. The addresses and email addresses can be found on the first page.

\section{References}

[1] D. Buschert, B. Bitzer, "Optimization of energy parks with biomass plants and water desalination", UPEC 2008 conference, Italy, South Westphalia University, Campus Soest, September 2008

[2] A. Hasnat, B. Bitzer, "Modeling and Simulation with TRANSYS - Best practice and development application for prototype Endohouse", MSc Project Report, January 2005

[3] M. Heppelmann, "Innovative optimization of a solar assisted heat pump system", $\mathrm{PhD}$ thesis, Bolton University and South Westphalia University, Campus Soest, April 2008

[4] M. Loeser, “Overview of Biomass Conversion and Generation Technologies”, UPEC 2008 conference, Italy, University of Bath, UK

[5] Terrawater, www.Terrawater.de

[6] LabVIEW, National Instruments, www.ni.com

[7] Aspen Tech, www.aspentech.com/

[8] Maplesoft, www.maplesoft.com

[9] Phase Diagram of Water, "Water on Mars”, http://www.aerospaceweb.org/question/astronomy/mars/water-phase.jpg 